\title{
A Study of Clinico-demographic Profile of Children with Presumptive Pulmonary Tuberculosis at Tertiary Health Care Institute
}

\author{
Baveja Sujata ${ }^{1}$, Nair Madhurima Suresh ${ }^{2 *}$, Swami Anjali $\mathrm{M}^{3}$ \\ ${ }^{1}$ Professor and HOD, ${ }^{2}$ Speciality Medical Officer, ${ }^{3}$ Associate Professor, Department of Microbiology, Lokmanya Tilak Municipal Medical \\ College and General Hospital, Sion, Mumbai, Maharashtra, INDIA. \\ Email: msnair1224@gmail.com
}

Abstract Background: Tuberculosis (TB) is an air borne disease caused by Mycobacterium tuberculosis. Though lung is the most common organ affected by TB, it can involve any organ system. TB is one of the leading causes of morbidity and mortality worldwide from an infectious disease. India has the highest TB burden in the world, with a considerable amount of cases falling in the age group 0-14 years. Hence childhood tuberculosis is a major concern in our country. Aims and Objectives: To study the clinico-demographic profile of children with presumptive pulmonary tuberculosis at a tertiary health care centre. Materials and Methods: A prospective study carried out in 120 clinically suspected cases of pulmonary TB in children in the age group 0 to 10 years. Data collected with pretested questionnaire. Data included demographic data, clinical features and risk factors. Patients were analysed for clinical profile and risk factors. Results: Male to female ratio was 1.2:1. Maximum number of cases $(30 \%)$ was in the age group 8-10 years. The most frequent symptoms in these children were cough $\geq 3 \mathrm{wks}$ and fever $(99.2 \%)$. Significantly higher percentage of cases $(54.2 \%)$ had history of TB contact. ESR was elevated in $84.2 \%$ of cases, whereas Mantoux test was positive in $59.2 \%$ cases and $37.5 \%$ had abnormal Chest X-ray findings suggestive of pulmonary TB. There was retroperitoneal lymphadenopathy in $66.7 \%$ of the cases and cervical lymphadenopathy was noted in 3.3\% cases. Conclusion: In children, TB is often missed or overlooked due to non-specific symptoms and difficulty in diagnosis. A majority of these cases are diagnosed on the basis of clinical suspicion supported by various investigation results. Presence of history of TB contact increases the risk of contracting childhood TB considerably.

Key Words: Tuberculosis, children, clinico-demographic profile.

\section{*Address for Correspondence:}

Dr. Madhurima Suresh Nair, Wimbeldon Park, Bldg No. 4, Flat No. 504, Opp. J.K. School, Pokharan Rd. No. 1, Thane (W), Maharashtra400606, INDIA.

Email: msnair1224@gmail.com

Received Date: 04/05/2020 Revised Date: 10/06/2020 Accepted Date: 14/07/2020

DOI: https://doi.org/10.26611/10081533

This work is licensed under a Creative Commons Attribution-NonCommercial 4.0 International License. $(\mathbf{( c )})$ EY-NC

\begin{tabular}{|l|l|}
\hline \multicolumn{2}{|c|}{ Access this article online } \\
\hline Quick Response Code: & Website: \\
& www.medpulse.in \\
\cline { 2 - 2 } & \\
\hline
\end{tabular}

\section{INTRODUCTION}

Tuberculosis, caused by Mycobacterium tuberculosis, still continues to be one of the world's deadliest communicable diseases. It typically affects the lungs (pulmonary TB), but other sites can also be affected (extra-pulmonary TB) such as pleura, lymph nodes, meninges, abdomen, genitourinary system, spine, bones and joints, etc. As per WHO Global Report 2018, an estimated 10.0 million people developed TB and 1.6 million died from the disease in the year 2017. Among those who developed TB disease in 2017, 5.8 million were men, 3.2 million were women and 1.0 million were children. India has the highest TB burden in the world accounting for $27 \%$ of the global cases with an estimated incidence of 2.74 million of which 2,24,000 were in the age group 0-14 years. ${ }^{1}$ Conventional pulmonary TB diagnosis is based mainly upon sputum microscopy, 
isolation of the causative organism on culture (solid or liquid medium), radiological or histopathological findings and clinical suspicion. ${ }^{2}$ In children, TB is often missed or overlooked due to non-specific symptoms and difficulty in diagnosis. Also, TB in children shows many clinical similarities with other common childhood diseases. In children, diagnosis of TB usually is dependent on discovery of a case in adults, tuberculin skin testing, chest radiograph and clinical signs and symptoms. But, none of these methods are fully reliable for diagnosing a case of childhood pulmonary TB. ${ }^{3,4}$

Tuberculosis has a major impact on the overall health of a child. This study was conducted to determine the clinicodemographic profile of children with presumptive pulmonary tuberculosis at a tertiary health care institute.

\section{MATERIALS AND METHODS}

Present study was a prospective study carried out in Department of Microbiology at a tertiary care hospital. Total 120 paediatric cases of Presumptive Pulmonary Tuberculosis were studied during $1^{\text {st }}$ January, 2017 to $31^{\text {st }}$ December, 2017.

Inclusion Criteria:

1. Children in the age group 0 to 10 years

2. Patients with clinical symptoms suggestive of pulmonary TB along with atleast any one factor like History of TB contact, Raised Erythrocyte Sedimentation Rate (ESR), Positive Mantoux Test [Positive Result- $\geq 10 \mathrm{~mm}$ ], Abnormal Radiological Findings suggestive of Pulmonary TB

3. Human Immunodeficiency Virus (HIV) negative patients.

Exclusion Criteria:

1. Age $>10$ years

2. Patients on Anti-tuberculosis treatment (ATT)

3. Human Immunodeficiency Virus (HIV) positive patients.

4. Parent/ guardian not giving consent for the study.

Study was approved by ethical committee of the institute. A valid written consent was taken from parent/ guardian of the patient after explaining the study to them.

Data was collected with pretested questionnaire. It included the demographic profile, presenting complaints, past history, investigations done for each patient and it was duly recorded in the case record form.

Statistical Analysis

Statistical analysis was performed with the software package: SPSS statistic 20 for Windows. The significance of difference of proportion of categorical variables among groups was examined by the chi-square test for large samples and Fischer's exact test for small samples. A value of $\mathrm{P}$ of $\leq 0.05$ was considered significant for all statistical analysis and was marked with an asterisk.

\section{RESULTS}

Out of the 120 cases included in this study, males comprised of $55 \%$ of the cases whereas females comprised of $45 \%$ (male to female ratio $=1.2: 1$ ) (table 1). Out of the 120 cases included in this study, maximum number of cases $(30 \%)$ were in the age group 8-10 years whereas minimum number of cases $(15.8 \%)$ were in the age group 0-2 years. Mean age was $6.1 \mathrm{yr}( \pm 3.1 \mathrm{yr})$ and median age was $7 \mathrm{yr}$, (range $0.1 \mathrm{yr}$ to $10 \mathrm{yr}$ ) (table2). Out of the 120 cases included in this study, $47.5 \%$ of the cases were inpatients whereas $52.5 \%$ were outpatients (table 3 ). Table 4 shows distribution of cases according to presenting symptoms. Cough $\geq 3 \mathrm{wks}$ and fever (99.2\%) were the most frequent symptoms followed by fatigue $(70.8 \%)$. Other symptoms seen were loss of appetite $(55 \%)$, weight loss $(31.7 \%)$, chest pain or pain during coughing/ breathing (20.8\%), chills $(10.8 \%)$, night sweats $(5 \%)$. Haemoptysis was not seen in any patient. Significantly higher percentage of cases $(54.2 \%)$ had history of TB contact. There was no past history of TB in these children (table 5). Table 6 shows distribution of cases based on ESR, Mantoux and Chest X-ray findings. ESR was elevated in $84.2 \%$ of cases, whereas Mantoux test was positive in $59.2 \%$ cases and $37.5 \%$ had abnormal Chest X-ray findings suggestive of pulmonary TB. This difference was statistically significant (Chi Square Value54.7, P Value- $<0.001 *$ ). There was Retroperitoneal Lymphadenopathy in $66.7 \%$ of the cases. This difference was statistically significant (Chi Square Value- 13.33, P Value- $\left.<0.001^{*}\right)$. Amongst the cases with Retroperitoneal Lymphadenopathy, $20 \%$ were necrotic and $80 \%$ were non-necrotic. This difference was statistically significant (Chi Square Value- 28.8, P Value- $<0.001 *$ ) (Table 7). Cervical Lymphadenopathy was noted in 3.3\% cases. This difference was statistically significant (Chi Square Value- 104.53, P Value- $<0.001 *)$. Amongst the cases with Cervical Lymphadenopathy, $25 \%$ were necrotic and $75 \%$ were non-necrotic (Table 8 ).

\begin{tabular}{cccc}
\multicolumn{3}{c}{ Table 1: Distribution of patients according to gender } \\
\hline Sr no & Gender & Number of cases & Percentage (\%) \\
\hline 1 & Female & 54 & 45 \\
2 & Male & 66 & 55 \\
& Total & 120 & 100 \\
\hline
\end{tabular}

\begin{tabular}{cccc}
\multicolumn{4}{c}{ Table 2: Distribution of patients according to age group } \\
\hline Sr no & Age-groups & Number of cases & Percentage (\%) \\
\hline 1 & $0-2 y r s$ & 19 & 15.8 \\
2 & $2-4 y r s$ & 20 & 16.7 \\
3 & $4-6 y r s$ & 20 & 16.7 \\
4 & $6-8 y r s$ & 25 & 20.8 \\
5 & $8-10 y r s$ & 36 & 30.0 \\
\hline & Total & 120 & 100.0
\end{tabular}


Table 3: Inpatient/outpatient distribution of cases

\begin{tabular}{|c|c|c|c|c|}
\hline Sr no & Inpatient/Outpatient & \multicolumn{2}{|c|}{ Number of cases } & Percentage (\%) \\
\hline 1 & Inpatient & & 57 & 47.5 \\
\hline \multirow[t]{2}{*}{2} & Outpatient & & 63 & 52.5 \\
\hline & Total & & 120 & 100.0 \\
\hline \multicolumn{5}{|c|}{$\begin{array}{l}\text { TABLE 4: Distribution of cases according to presenting symptoms } \\
\qquad(n=120)\end{array}$} \\
\hline \multicolumn{2}{|r|}{ PRESENTING SYMPTOMS } & & Number & Percentage (\%) \\
\hline \multirow{2}{*}{\multicolumn{2}{|c|}{ Cough $\geq 3$ wks }} & Yes & 119 & 99.2 \\
\hline & & No & 1 & 0.8 \\
\hline \multirow{2}{*}{\multicolumn{2}{|c|}{ Haemoptysis }} & Yes & 0 & 0.0 \\
\hline & & No & 120 & 100 \\
\hline \multirow{2}{*}{\multicolumn{2}{|c|}{$\begin{array}{l}\text { Chest pain/pain with } \\
\text { breathing or coughing }\end{array}$}} & Yes & 25 & 20.8 \\
\hline & & No & 95 & 79.2 \\
\hline \multirow{2}{*}{\multicolumn{2}{|c|}{ Weight loss }} & Yes & 38 & 31.7 \\
\hline & & No & 82 & 68.3 \\
\hline \multirow{2}{*}{\multicolumn{2}{|c|}{ Fatigue }} & Yes & 85 & 70.8 \\
\hline & & No & 35 & 29.2 \\
\hline \multirow{2}{*}{\multicolumn{2}{|c|}{ Fever }} & Yes & 119 & 99.2 \\
\hline & & No & 1 & 0.8 \\
\hline \multirow{2}{*}{\multicolumn{2}{|c|}{ Night sweats }} & Yes & 6 & 5.0 \\
\hline & & No & 114 & 95 \\
\hline \multirow{2}{*}{\multicolumn{2}{|c|}{ Chills }} & Yes & 13 & 10.8 \\
\hline & & No & 107 & 89.2 \\
\hline \multirow{2}{*}{\multicolumn{2}{|c|}{ Loss of appetite }} & Yes & 66 & 55 \\
\hline & & No & 54 & 45 \\
\hline
\end{tabular}

Table 5: Distribution of cases based on past history of TB and history of TB contact $(n=120)$

\begin{tabular}{cccc}
\hline & & Number & Percentage \\
\hline Past history of TB & Yes & 0 & 0 \\
& No & 120 & 100 \\
History of TB Contact & Yes & 65 & 54.2 \\
& No & 55 & 45.8 \\
\hline Chi Square Value- 89.1 & & \multicolumn{2}{c}{ P Value- $<0.001^{*}$}
\end{tabular}

Table 6: Distribution of cases based on ESR, Mantoux and Chest X-

\begin{tabular}{|c|c|c|c|}
\hline TEST & & Number & $\%$ \\
\hline \multirow{3}{*}{$\begin{array}{c}\text { ESR } \\
\text { (Normal range }=0-13 \\
\mathrm{~mm} / \mathrm{hr} \text { ) }\end{array}$} & Within normal & 19 & 15.8 \\
\hline & limits & & \\
\hline & Raised & 101 & 84.2 \\
\hline \multirow{3}{*}{$\begin{array}{l}\text { Mantoux test } \\
\text { (Positive result= } \\
\geq 10 \mathrm{~mm} \text { ) }\end{array}$} & Within normal & 49 & 40.8 \\
\hline & limits & & \\
\hline & Raised & 71 & 59.2 \\
\hline \multirow[t]{2}{*}{ Chest X-ray } & Normal & 75 & 62.5 \\
\hline & Abnormal & 45 & 37.5 \\
\hline i Square Value- 54.7 & & P Value & $001^{*}$ \\
\hline
\end{tabular}

Table 7: Distribution of cases based on retroperitoneal lymphadenopathy on Ultrasonography (USG)

\begin{tabular}{lccc} 
USG- Retroperitoneal lymph nodes & $\begin{array}{c}\text { No. of } \\
\text { cases }\end{array}$ & Percentage (\%) \\
\hline Lymphadenopathy & Necrotic & 16 & 13.3 \\
& Non necrotic & 64 & 53.4 \\
Nothing Abnormal Detected & 40 & 33.3 \\
\multicolumn{2}{c}{ Total } & 120 & 100.0
\end{tabular}

Table 8: Distribution of cases based on cervical lymphadenopathy on USG Neck

\begin{tabular}{cccc} 
USG Neck & No. of cases & Percentage (\%) \\
Cervical & Necrotic & 1 & 0.8 \\
mphadenopathy & Non necrotic & 3 & 2.5 \\
Nothing abnormal detected & 116 & 96.7 \\
\multicolumn{2}{c}{ Total } & 120 & 100.0
\end{tabular}

\section{DISCUSSION}

In the present study, out of the 120 cases, males comprised of $55 \%$ of the cases whereas females comprised of $45 \%$ with male to female ratio of $1.2: 1$. In a study by Moussa HS et $a l .{ }^{3}$ in 2016, maximum number of cases were males, that is, $60.9 \%$ while females accounted for only $39.1 \%$ of the total cases with male to female ratio of $1.6: 1$. In a study by Hasan $\mathrm{Z}$ et al.. ${ }^{5}$ in 2017 , males comprised of $56 \%$ of the cases whereas females comprised of $44 \%$ with male to female ratio of 1.2:1. These findings were concordant with the present study. In a study by Memon SS et al. ${ }^{6}$ in 2018, males comprised $41 \%$ of the cases while females comprised $59 \%$ of the cases with a male to female ratio of $0.7: 1$. In a study by Walters E et al. $^{7}$ in 2012, males comprised of $46.4 \%$ of the cases whereas female comprised of $53.6 \%$ with male to female ratio of $0.9: 1$. These findings were discordant with the present study. In the present study, out of the 120 cases, maximum number of cases (30\%) was in the age group 8-10 years whereas minimum number of cases $(15.8 \%)$ was in the age group 0-2 years. Mean age was $6.1 \mathrm{yr}( \pm 3.1 \mathrm{yr})$ and median age was $7 \mathrm{yr}$, (range $0.1 \mathrm{yr}$ to $10 \mathrm{yr}$ ). In a study by Memon SS et al. ${ }^{6}$ in 2018, maximum number of cases $(58 \%)$ was in the age group 10-15 years whereas minimum number of cases $(16 \%)$ was in the age group 0-5 years. Mean age was $9.98 \mathrm{yr}( \pm 3.67 \mathrm{yr})$ and median age was $11 \mathrm{yr}$. In a study by Hasan $\mathrm{Z}$ et $a .^{5}$ in 2017 , which included subjects in the ages ranging from 7 months to 15 years, the median age was 6.8 years. These findings were similar to the present study. In a study by Walters E et al. ${ }^{7}$ in 2012, in which children less than 14 years of age were enrolled, the median age was 17.2 months. In a study by Nicol MP et al. ${ }^{8}$ in 2013, in which children less than 15 years of age were enrolled, the median age was 31 months. These findings were discordant with the present study. In the present study, out of the 120 cases, $47.5 \%$ of the cases were inpatients whereas $52.5 \%$ were outpatients. In a study by Nicol MP et al. ${ }^{8}$ in $2013,58.3 \%$ were inpatients. This finding was discordant with the present study. In the present study, out of the 120 cases, cough $\geq 3 \mathrm{wks}$ and fever $(99.2 \%)$ were the most frequent symptoms 
followed by fatigue $(70.8 \%)$, loss of appetite $(55 \%)$, weight loss $(31.7 \%)$, chest pain/pain with breathing or coughing $(20.8 \%)$ and chills $(10.8 \%)$; none of the patients presented with haemoptysis. In a study by Moussa HS et al. ${ }^{3}$ in 2016 , persisting cough $(86.1 \%)$ was the most common symptom followed by night sweat $(77.4 \%)$, fever $\geq 1$ week $(66.1 \%)$ and weight loss (30.1\%). In a study by Chipinduro M et al. ${ }^{9}$ in 2017, weight loss was the most common symptom with which the patients presented followed by fever and night sweats. Both the studies show that paediatric TB presents with non-specific symptoms and shows many clinical similarities with other common childhood diseases. Childhood TB is acquired usually from an infectious adult contact. ${ }^{10}$ Mycobacterium tuberculosis (MTB) infection usually occurs by inhalation of tubercle bacilli in aerosolised respiratory droplets derived from an infectious case of pulmonary TB. Therefore, risk of infection is dependent on the probability, duration and proximity of exposure to an infectious case, and on the infectiousness of the source. In case of childhood TB, this is usually an adult with cavitatory pulmonary disease, although older children may also contribute to transmission. ${ }^{11}$ In the present study, out of the 120 cases, significantly higher percentage of cases $(54.2 \%)$ had history of TB contact. There was no past history of TB in these children. In a study by Hasan Z et al. ${ }^{5}$ in $2017,56 \%$ of child TB cases had contact with an adult TB patient. This finding was concordant with the present study. In a study by Moussa HS et al. $^{3}$ in 2016, 38.2\% cases had history of TB contact. In a study by Chipinduro $\mathrm{M}$ et al. ${ }^{9}$ in $2017,23.4 \%$ cases had history of TB contact and $7.8 \%$ cases had history of TB in the past. These findings were discordant with the present study. In the present study, out of the 120 cases, ESR was elevated in $84.2 \%$ of cases, whereas Mantoux test was positive in $59.2 \%$ cases and $37.5 \%$ had abnormal Chest Xray findings suggestive of pulmonary TB. In a study by Moussa HS et al. ${ }^{3}$ in 2016, $11.3 \%$ case had positive Mantoux test and $83.5 \%$ cases had Chest X-ray findings consistent with TB. These findings were discordant with the present study. According to a study by Scheepers S et al. ${ }^{12}$ in 2011 , diagnosis of PTB using abdominal lymphadenopathy as a surrogate for mediastinal lymphadenopathy may present a simple and accurate additional diagnostic technique that is of value in developing countries. In the present study, out of the 120 cases, there was Retroperitoneal Lymphadenopathy in $66.7 \%$ of the cases. Amongst the cases with Retroperitoneal Lymphadenopathy, 20\% were necrotic and $80 \%$ were non-necrotic. In the present study, cervical lymphadenopathy was noted in $3.3 \%$ cases. Amongst the cases with Cervical Lymphadenopathy, 25\% were necrotic and $75 \%$ were non-necrotic.

\section{CONCLUSION}

In children, TB is often missed or overlooked due to nonspecific symptoms and difficulty in diagnosis. A majority of these cases are diagnosed on the basis of clinical suspicion supported by various investigation results. Presence of history of $\mathrm{TB}$ contact increases the risk of contracting childhood TB considerably.

\section{REFERENCES}

1. WHO Global Tuberculosis Report, 2018. Available from http://www.who.int/tb/publications/global_report/en/ [Last accessed on $9^{\text {th }}$ November, 2018]

2. Ryu YJ. Diagnosis of pulmonary tuberculosis: recent advances and diagnostic algorithms. Tuberc Respir Dis (Seoul). 2015;78(2):64-71.

3. Moussa HS, Bayoumi FS, Mohamed AM. Gene Xpert for Direct Detection of Mycobacterium Tuberculosis in Stool Specimens from Children with Presumptive Pulmonary Tuberculosis. Ann Clin Lab Sci. 2016; 46(2):198-203.

4. Khan EA, Starke JR. Diagnosis of tuberculosis in children: increased need for better methods. Emerging infectious diseases. 1995;1(4):115.

5. Hasan Z, Shakoor S, Arif F, Mehnaz A, Akber A, Haider M, et al.. Evaluation of Xpert MTB/RIF testing for rapid diagnosis of childhood pulmonary tuberculosis in children by Xpert MTB/RIF testing of stool samples in a low resource setting. BMC Res Notes. 2017;10(1):473.

6. Memon SS, Sinha S, Sharm SK, Kabra SK, Lodha R, Soneja M.Diagnostic Accuracy of Xpert Mtb/Rif Assay in Stool Samples in Intrathoracic Childhood Tuberculosis. $J$ Tuberc Ther 2018;3(2): 115

7. Walters E, Gie RP, Hesseling AC, Friedrich SO, Diacon AH, Gie RP. Rapid diagnosis of pediatric intrathoracic tuberculosis from stool samples using the Xpert MTB/RIF Assay: a pilot study. Pediatr Infect Dis J. 2012;31(12):1316

8. Nicol MP, Spiers K, Workman L, Isaacs W, Munro J, Black F, et al.. Xpert MTB/RIF testing of stool samples for the diagnosis of pulmonary tuberculosis in children. Clin Infect Dis. 2013;57(3):e18-21.

9. Chipinduro M, Mateveke K, Makamure B, Ferrand RA, Gomo E. Stool Xpert ${ }^{\mathbb{B}} \mathrm{MTB} / \mathrm{RIF}$ test for the diagnosis of childhood pulmonary tuberculosis at primary clinics in Zimbabwe. Int $J$ Tuberc Lung Dis. 2017;21(2):161-166.

10. Tsai KS, Chang HL, Chien ST, Chen KL, Chen KH, Mai MH, et al. Childhood Tuberculosis: Epidemiology, Diagnosis, Treatment, and Vaccination. Pediatrics and Neonatology. 2013;54(5): 295-302.

11. Newton SM, Brent AJ, Anderson S, Whittaker E, Kampmann B. Paediatric Tuberculosis. Lancet Infect Dis. 2008;8(8):498-510

12. Scheepers S, Andronikou S, Mapukata A, Donald P. Abdominal lymphadenopathy in children with tuberculosis presenting with respiratory symptoms. Ultrasound. 2011;19(3):134-139.

\section{Source of Support: None Declared Conflict of Interest: None Declared}

Policy for Articles with Open Access:

Authors who publish with MedPulse International Journal of Microbiology (Print ISSN: 2550-7648) (Online ISSN: 2636-4646) agree to the following terms: Authors retain copyright and grant the journal right of first publication with the work simultaneously licensed under a Creative Commons Attribution License that allows others to share the work with an acknowledgement of the work's authorship and initial publication in this journal.

Authors are permitted and encouraged to post links to their work online (e.g., in institutional repositories or on their website) prior to and during the submission process, as it can lead to productive exchanges, as well as earlier and greater citation of published work. 